\title{
STRATEGIES FOR IMPROVING ELECTROSPINABILITY OF POLYSULFONE
}

\author{
Iman Azarian Borojeni, Biao Zhou ${ }^{1}$ \\ Department of Mechanical, Automotive, and Materials \\ Engineering \\ University of Windsor, Windsor, Canada
}

\author{
S. Holger Eichhorn \\ Department of Chemistry and Biochemistry \\ University of Windsor, Windsor, Canada
}

\begin{abstract}
The overall objective of this study is the fabrication of defect-free electrospun mats of polysulfone (PSU) for applications as a porous support for proton exchange membranes. Electrospinning of PSU from dimethylformamide (DMF) solution generated mats free of cast formation and over-wetting, but unspun droplets were frequently observed in the mats because the electrospun jet was unstable. A stable jet and a large reduction of beads in the electrospun mats were obtained with a mixture of 20 vol. \% acetone in DMF. Subsequent optomization of the flow rate to $1.5 \mathrm{~mL} / \mathrm{h}$ and the applied voltage to $14 \mathrm{kV}$ generated electrospun mats free of any beads based on SEM analysis.
\end{abstract}

Keywords-component; Electrospinning; polysulfone (PSU); Dimethylformamide (DMF); Proton Exchange Membrane Fuel Cell (PEMFC)

\section{INTRODUCTION}

Proton Proton Exchange Membrane Fuel Cell (PEMFC) is one of the proposed effective methods to improve the energy conversion in vehicles due to their high efficiency and no hazardous emission [1]. However, there are still several barriers, such as high production cost and low durability, that need to be addressed for commercial development. Several deficiencies are rooted in the perfomance of the membranes PEMFCs, which is why the improvement of these membranes is a present focus of fuel cell related research [2].

The most broadly applied membrane materials are perflourosulfonic acids (PFSA), which show high proton conductivity at a fully hydrated state. However, they suffer from a high price and low dimensional stability during the starting up and shutting down of a PEMFC when the amount of humidity is varied widely $[2,3]$. To overcome this issue, the commercial membranes have relatively high thickness (50$175 \mu \mathrm{m})$ to show enough strength to overcome the changes in dimensions. However, thicker membranes negatively impact the performance of the fuel cell due to their decreased proton conductance [3].

${ }^{1}$ Corresponding Author and Principal Investigator: Dr. Biao Zhou, bzhou@uwindsor.ca, 1-519-253-3000 ext. 2630
One of the proposed methods for reducing the thickness of the membrane without decreasing the durability of the fuel cell is to build a porous inert reinforcement into the membrane to limit its expansion and contraction when its water content is changed. The inforcement porpous support would also improve the mechanical properties of the membrane and is expected to reduce the overall cost of production. The overall cost is likely reduced despite extra processing steps because the porous enforcment material is much less expensive than PFSA and the overall amount of required PFSA is significantly reduced [2].

Among different methods for the fabrication of porous support layers, electrospinning attracts great attention due to its ability to fabricate submicron fibers mats with different morphologies [4]. Typically, a high voltage power supply (usually in the $\mathrm{kV}$ range) connects to a collector and the conductive needle of a syringe. The syringe is filled with a viscous liquid (a polymer solution or a molten polymer) to charge it. At a certain critical voltage, the repulsive force of the charged liquid offsets its surface tension and the liquid ejects from the nozzle to the collector. If the polymer solution has enough entanglement, the ejected solution forms fibers and the process is called electrospinning; otherwise, the ejected solution turns into small droplets and the process is called electrospraying [5, 6]. Simplicity, ability to control morphology at different levels makes this method attractive to researchers [4]. Moreover, the uniaxial alignment of polymer chain fibers can improve the mechanical properties of the membrane [7]. Finally, the low packing density of generated electrospun mats and their interconnected pore structure make them excellent substrates for filling with other materials to fabricate a dense membrane. Several polymers, such as polyvinylidene fluoride (PVDF), polyvinyl alcohol (PVA), Polystyrene (PS), and polysulfone (PSU) have been successfully electrospun as the porous support for proton exchange membranes [7]. However, more investigations are required to improve the electrospinning condition of these polymers for their application in a proton exchange membrane. 
Reported here is the electrospinnig behaviour of PSU in dimethylformamide-acetone mixtures and the effect of the electrospinning parameters on the morphology of the produced mats. Specifically, adjutments of the acetone content, flow rate, and voltage successfully suppressed the formation of macroscopic and microscopic defects observed for not optimized spinning conditions..

\section{EXPERIMENTAL PROCEDURE}

N,N-Dimethylformamide (DMF, anhydrous, 99.8\%) and Polysulfone (PSU, average $\mathrm{Mn} \approx 22,000$ ) were purchased from Sigma-Aldrich. Acetone (ACS grade) was also provided from VWR. Solvents with different volume ratios of acetone in DMF $(0 \%, 20 \%$, and $40 \%)$ were prepared and used for the preparation of PSU solutions at a concentration of $20 \mathrm{wt} \%$. The mixtures were stirred via a magnet stirrer for 6 hours to generate a homogeneous solution at room temperature. The solutions were kept overnight at room temperature to ensure no phase separation occurs. Only solutions that show no macroscopic phase separation were selected for electrospinning test.

Before electrospinning, the solution was stirred for 2 hours to homogenise again. A $5 \mathrm{cc}$ plastic syringe was filled bubble free and connected to a 22 gauge stainless steel blunt needle. The syringe was loaded onto a syringe pump (KDS, Legato 200) to control the flow rate $(0.2$ to $1.5 \mathrm{~mL} / \mathrm{h})$. To charge up the solution for electropsinning, a power supply (ES50, Gamma high voltage research) was connected to the needle and a grounded static steel plate covered by an aluminum foil that served as the current collector. The current collector was placed 10 to $20 \mathrm{~cm}$ from the needle tip and the applied voltage was varied between $10 \mathrm{kV}$ and $30 \mathrm{kV}$. The applied voltage was usually selected based on the critical voltage for ejection of the fluid from the Taylor cone (1 to $2 \mathrm{kV}$ higher than the critical voltage), but in a few cases voltages $7 \mathrm{kV}$ higher than the critical voltage were also examined to stabilize the process and avoid the formation of unspun droplets.

The electrospun samples were dried at $65{ }^{\circ} \mathrm{C}$ overnight to remove any possible residual solvent and then coated with gold by sputtering for the observation by SEM (Field Emission Scanning Electron Microscope Quanta FEG 200).

\section{RESULT AND DISCUSSION}

Before In our first experiments, pure DMF was used as the solvent for PSU. PSU showed appropriate solubility in DMF and clear solutions were obtained easily by stirring at room temperature. Electrospiining of these solutions was also straightforward and no cracking, cast formation, or peeling off was observed in the electrospun mats. However, the electrospun jet was not stable and unspun droplets were frequently observed during the process, which led to the formation of dotted patterns in the electrospun mats (Fig. 1-a). Although the problem was supposed to be addressed by reducing the flow rate [8], it became worse in our hands (Fig. $1-b)$.
The microstructure of the electrospun mats also suffered from the formation of beads. Fig. 2 shows the microstructure of the fabricated mats when the distance between the needle's tip and the collector was 20 and $15 \mathrm{~cm}$, respectively. Although the number of beads can be reduced effectively by optimizing the tip collector distance (d) the formation of unspun droplets still persisted. To address this issue, DMF-acetone mixtures were applied as the solvent for PSU to reduce the surface tension of the solvent. If the surface tension is reduced, the beads problem can be addressed effectively and the formation of unspun droplets is reduced because the electrospun jet is more stable.

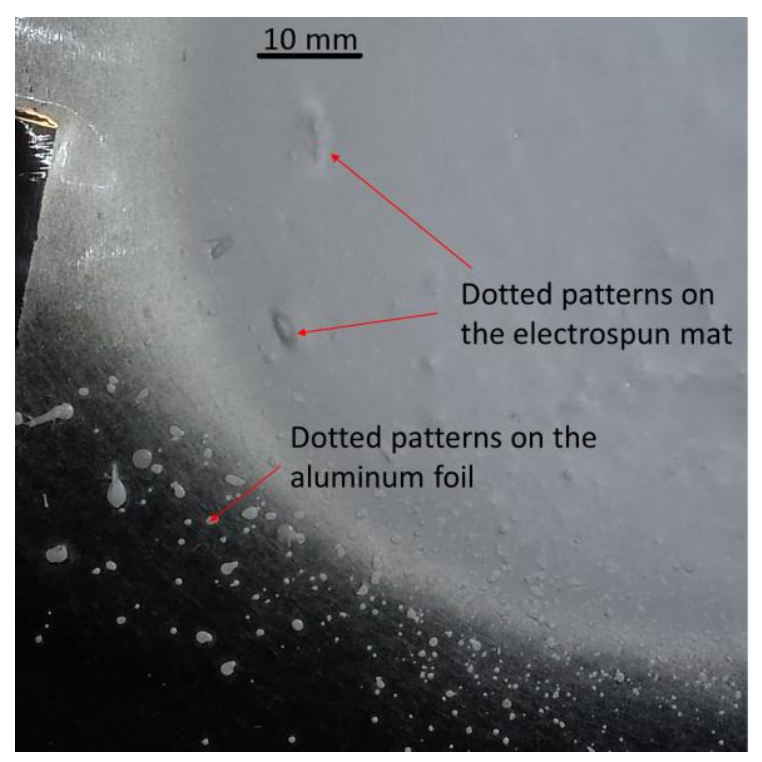

(a)

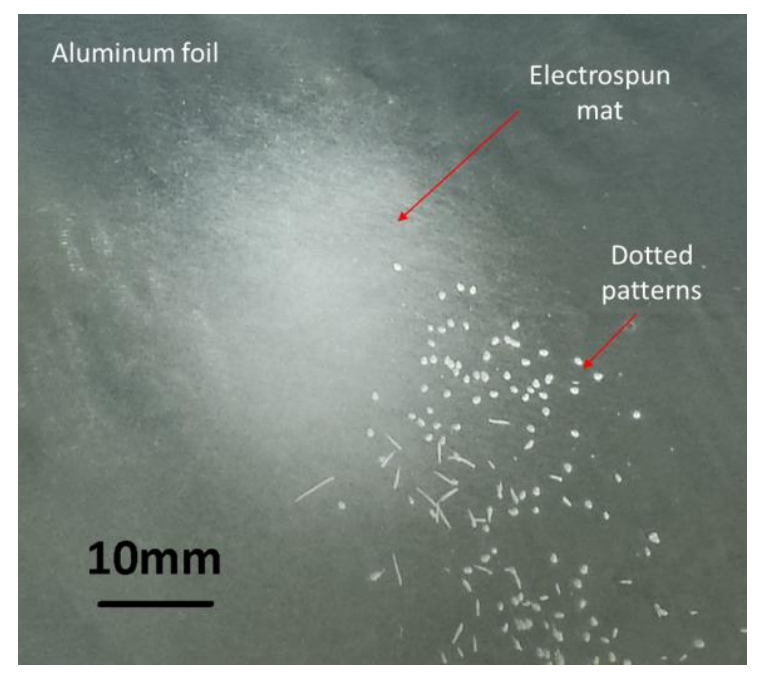

(b)

Figure 1. The PSU electrospun mat from DMF solution when the needle tip to collector distance is $15 \mathrm{~cm}$ : (a) flow rate $=0.5 \mathrm{~mL} / \mathrm{h}$ (b) flow rate $=0.2$ $\mathrm{mL} / \mathrm{h}$. 




(a)

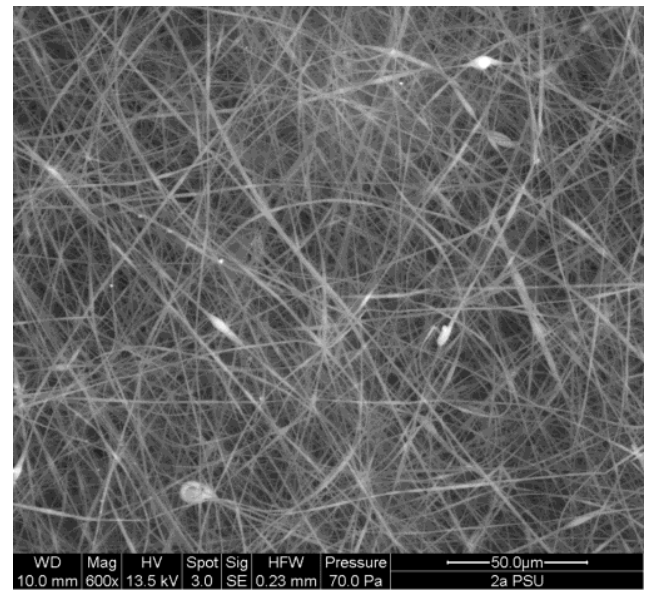

(b)

Figure 2. SEM images of the PSU electrospun fibers when DMF is applied as the solvent and the flow rate is $0.5 \mathrm{~mL} / \mathrm{h}$ : (a) $\mathrm{d}=20 \mathrm{~cm}$ (b) $\mathrm{d}=15 \mathrm{~cm}$.

PSU did not show proper solubility in 60\%DMF-40\% acetone (by Vol.) mixture. The solution was not clear and a macroscopic phase separation was observed after one day (a clear solution was on top and a milky solution was in bottom). By increasing the percentage of DMF to $80 \%$, the solubility improved remarkably. Although the prepared solution was milky again, no macroscopic phase separation was observed even within a week.

By replacing the solvent from pure DMF to a mixture of $80 \%$ DMF and $20 \%$ acetone, some differences were observed in the electrospinning process. Firstly, the critical voltage for the Taylor cone was reduced significantly. The critical applied voltage for pure DMF was around $29 \mathrm{kV}$ when the needle tip collector distance was $15 \mathrm{~cm}$ while this value for a $4: 1$ DMF/acetone mixture was just $8 \mathrm{kV}$. Since in many mathematical models the critical voltage mostly depends on the surface tension (among other solution parameters such as viscosity and conductivity) [6], reduction of the surface tension by the addition of acetone seemed to play an important role in the reduction of the critical voltage.

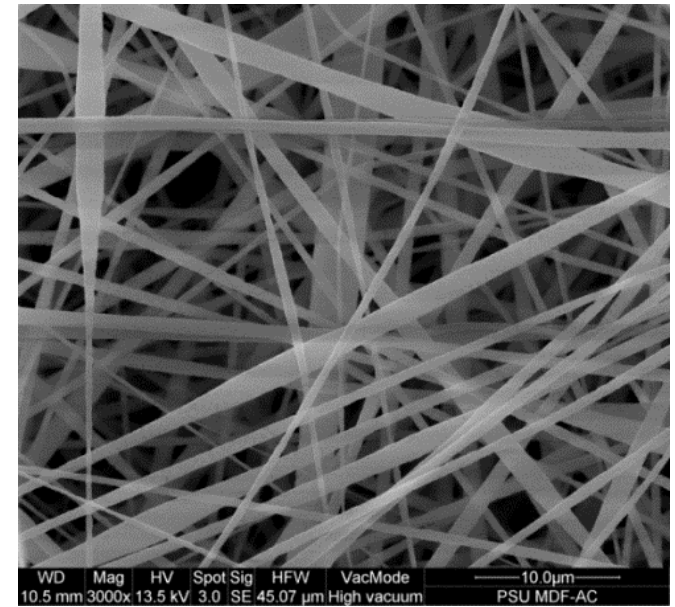

(a)

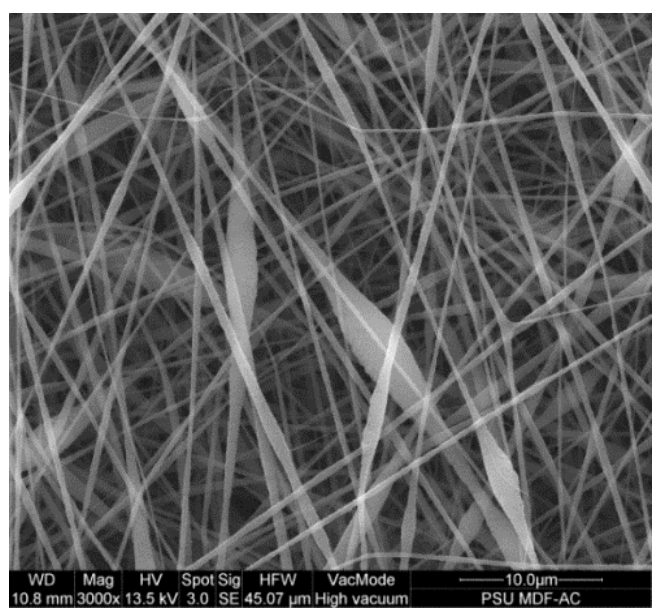

(b)

Figure 3. The SEM images of PSU electrospun fibers when $80 \%$ DMF$20 \%$ acetone was used as the solvent, the applied voltage was $10 \mathrm{kV}$ and $\mathrm{d}=15 \mathrm{~cm}$ : (a) flow rate $=1.2 \mathrm{~mL} / \mathrm{h}$, (b) flow rate $=0.2 \mathrm{~mL} / \mathrm{h}$.

Addition of acetone also affected the microstructure of the electrospun mats. The beads were almost removed in the microstructure due to reduction of the surface tension of the solution (Fig. 3-a). It should be mentioned that the driving force for the bead formation is the high surface energy of the electrspun fibers during the electrospinning process [9]. Therefore, reduction of the surface energy can address this problem significantly.

Additionally, the electrospun jet became more stable when acetone was added to the solution. It was reported that the jet become more stable when the surface tension of the solution was reduced [9]. The unspun droplets were still persistence, but the number of them was cut down effectively. To diminish this problem totally other electrospinning parameters should be tuned. Reduction of the flow rate is one of the effective strategies that has been recommended to address the formation of unspun droplets [8]. However, similar to the case of using pure DMF, reduction of the flow rate to $0.2 \mathrm{~mL} / \mathrm{h}$ was not only unable to improve the stability of the electrospun jet, but made 


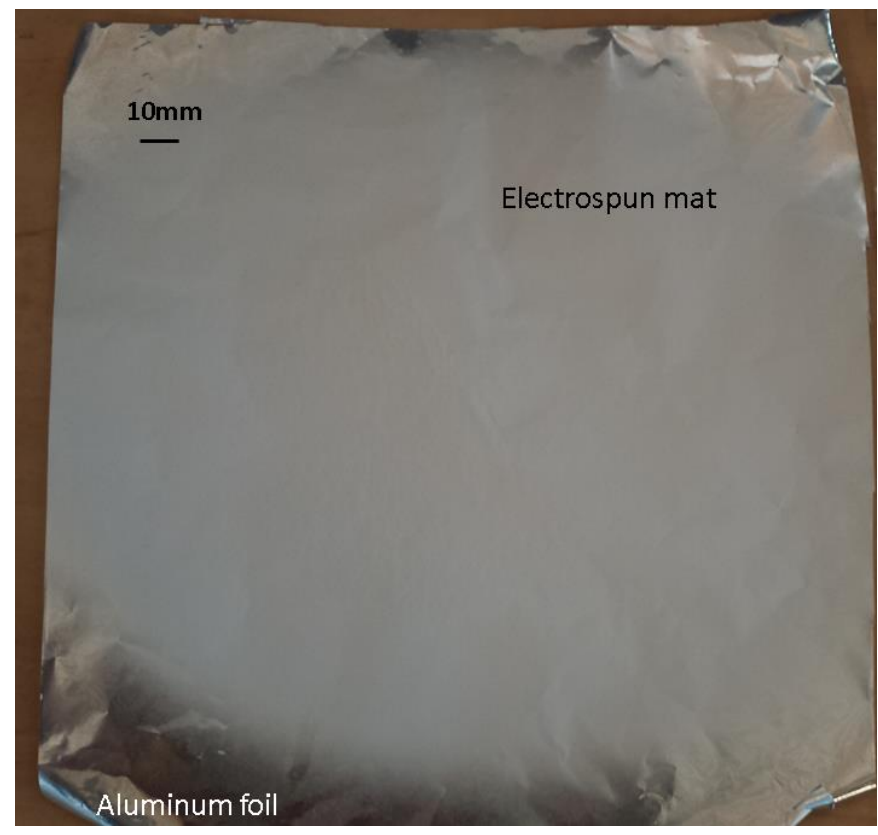

Figure 4. The PSU electrospun mat from $80 \%$ DMF-20\% acetone solvent when the applied voltage was $14 \mathrm{kV}$, flow rate was $1.5 \mathrm{~mL} / \mathrm{h}$ and $\mathrm{d}=15 \mathrm{~cm}$.

it less stable. This generated more unspun droplets and more beads appeared in the microstructures (Fig. 3-b).

Surprisingly, the higher flow rate $(1.5 \mathrm{~mL} / \mathrm{h})$ remarkably improved the stability of the jet. To achieve a fully stable jet and completely avoid the formation of unspun droplets, the applied voltage was increased to $14 \mathrm{kV}$. Only under this condition we were able to fully suppress the formation of unspun droplets and avoid the formation of dotted pattern of (Fig. 4). Fig. 5 illustrates the microstructures of the electrospun mats when the needle tip collector distance (d) was varied from 10 to $20 \mathrm{~cm}$ and the mentioned adjustment on the flow rate and the voltage were applied. The microstructures of the electrospun mats for $\mathrm{d}=15 \mathrm{~cm}$ or $20 \mathrm{~cm}$ were almost the same, although very few beads can be spotted for $\mathrm{d}=20 \mathrm{~cm}$. The beads were diminished when $\mathrm{d}=15 \mathrm{~cm}$. However, by reduction of $\mathrm{d}$ to $10 \mathrm{~cm}$, the surface of the fibers became rough and some particles like structure were formed, which had different structure from the electrospun fibers (Fig. 5-c and Fig. 6).

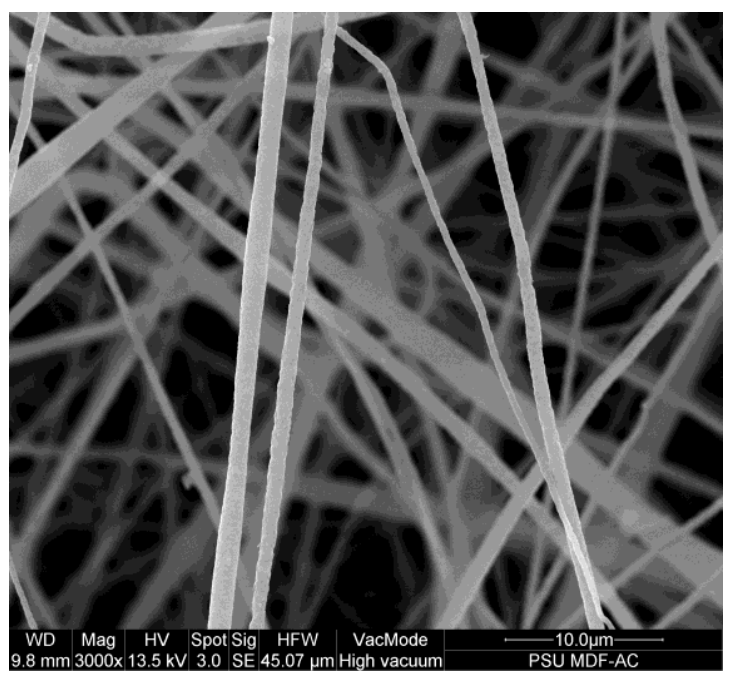

(a)

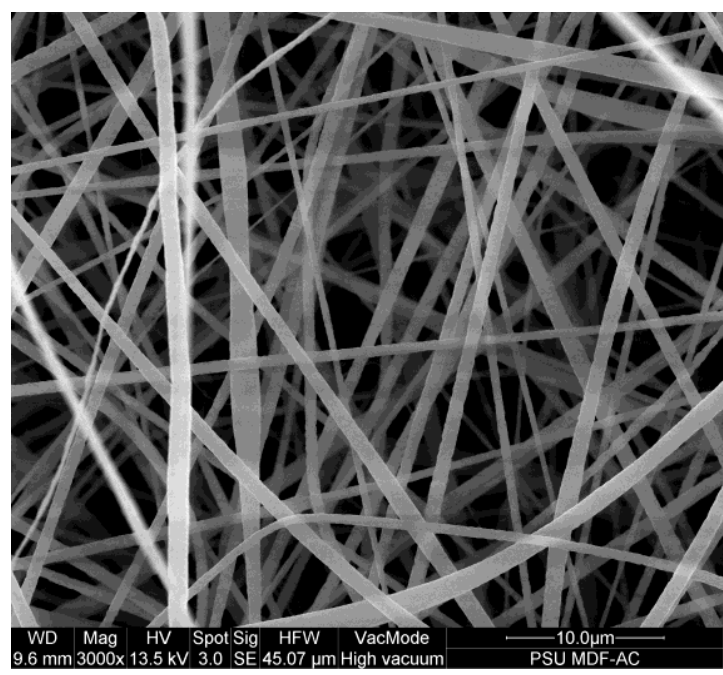

(b)

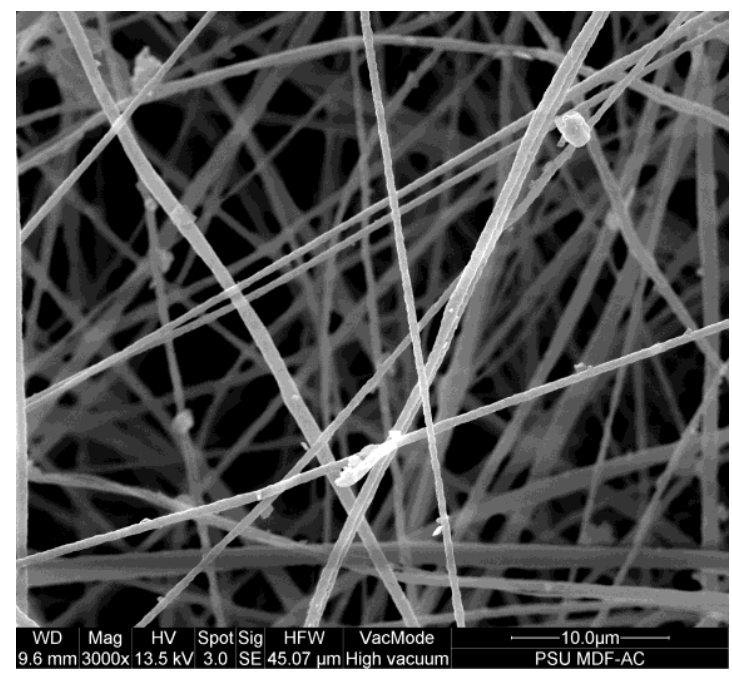

(c)

Figure 5. The SEM micrograph of the PSU electrospun fibers when $80 \%$ DMF-20\% acetone solvent when the applied voltage was $14 \mathrm{kV}$, flow rate was $1.5 \mathrm{~mL} / \mathrm{h}$ : (a) $\mathrm{d}=20 \mathrm{~cm}$, (b) $\mathrm{d}=15 \mathrm{~cm}$, (c) $\mathrm{d}=10 \mathrm{~cm}$. 




Figure 6 The SEM image of particle-like defect when 80\% DMF-20\% acetone solvent when the applied voltage was $14 \mathrm{kV}$, flow rate was $1.5 \mathrm{~mL} / \mathrm{h}$ and $\mathrm{d}=10 \mathrm{~cm}$.

\section{SUMMARY}

We were not successful in the optimization of electrospinning parameters to generate defect-free mats with PSU solutions in DMF. This was mainly caused by an unstable jet that resulted in the formation of unspun droplets and a dotted pattern on the collector. Another manifestation of unsuitable spinning parameters was the formation of large numbers of beads in the mats. A stable jet and defect free electrospun mats were obtained with a solvent mixture of DMF/acetone 4:1 that has a drastically reduced surface tension. The collector distance, applied voltage, and flow rate were optimized to $15 \mathrm{~cm}, 1.5 \mathrm{~mL} / \mathrm{h}$, and $14 \mathrm{kV}$, respectively.

\section{ACKNOWLEDGMENT}

The authors are grateful for the support from the Natural Sciences and Engineering Research Council of Canada (NSERC) and the University of Windsor.

\section{REFERENCES}

[1] D. J. Kim, M. J. Jo, and S. Y. Nam, "A review of polymernanocomposite electrolyte membranes for fuel cell application," J. Ind. Eng. Chem., vol. 21, pp. 36-52, 2015.

[2] C. Houchins, G. Kleen, J. Spendelow, J. Kopasz, D. Peterson, N. Garland, D. Ho, J. Marcinkoski, K. Martin, R. Tyler, and D. Papageorgopoulos, "U.S. DOE Progress Towards Developing Low-Cost, High Performance, Durable Polymer Electrolyte Membranes for Fuel Cell Applications," Membranes, vol. 2, pp. 855-878, 2012.

[3] S. Banerjee, D. N. Prugh, and S. Frisk, "Advances in Proton Exchange Membrane Technology," ECS Transactions, vol. 50, pp. 887-895, 2013.

[4] B. Ding, J. Yu on Electrospun nanofibers for energy and environmental applications, 1st ed., Springer: Berlin Heidelberg, 2014, pp.3-38.

[5] A. Greiner and J. H. Wendroff, "Electrospinning: A Fascinating Method for the Preparation of Ultrathin Fibers," ChemInform, vol. 38, 2007.
[6] M. Afshari on Electrospun nanofibers, 1 st ed., Elsevier: Waltham, 2017, pp303-337.

[7] R. Sood, S. Cavaliere, D. J. Jones, and J. Rozière, "Electrospun nanofibre composite polymer electrolyte fuel cell and electrolysis membranes," Nano Energy, vol. 26, pp. 729-745, 2016.

[8] A. Haider, S. Haider, and I.-K. Kang, "A comprehensive review summarizing the effect of electrospinning parameters and potential applications of nanofibers in biomedical and biotechnology," Arab. J. Chem., 2015.

[9] Electrospinning: A fascinating fiber fabrication technique N. Bhardwaj and S. C. Kundu, "Electrospinning: A fascinating fiber fabrication technique," Biotechnol. Adv., vol. 28, pp. 325-347, 2010. 